\title{
La necesidad de la mediación comunitaria en las sociedades actuales
}

\author{
The need for community mediation in today's societies
}

\begin{abstract}
Eduardo Barajas Langurén* Judith Vanessa Gómez Higuera**

* Doctor en Derecho por la Universidad Autónoma de Nuevo León, con Maestría en Administración de la Justicia y Seguridad Pública, Abogado, Profesor Investigador de Tiempo Completo, en el Centro Universitario de la Ciénega, sede Ocotlán, de la Universidad de Guadalajara, Profesor con perfil deseable PRODEP, miembro y líder del Cuerpo Académico Derechos Humanos y Seguridad Ciudadana, ha pertenecido al Sistema Nacional de Investigadores del CONACYT, ebarajas9@yahoo.com.mx.

**Estudiante de último año de la carrera de derecho, candidata a abogada en la Universidad Autónoma de Bucaramanga (UNAB), Conciliadora extrajudicial en derecho por la UNAB, Participante investigadora del semillero de Derechos Humanos y Derecho Internacional Humanitario "EPOJE" del centro de Investigaciones socio jurídicos adscrito a la UNAB, jgomez726@unab.edu.co
\end{abstract}

Fecha de recepción: marzo de 2020

Fecha de aprobación: diciembre de 2020

Para citar este artículo / To reference this article

Barajas, E., Gómez, J.V (2020) La necesidad de mediación comunitaria en las sociedades actuales. Inciso, 22(2) ; $182-202$

\section{Resumen}

DOI: http://dx.doi.org/10.18634/incj.22v.2i. 1085

El propósito de la presente investigación, es resaltar la importancia de la mediación comunitaria en la sociedad, donde conservar, asegurar el orden y la paz social, son responsabilidades del Estado con estrecha relación con el derecho, empleando la metodología documental o indirecta, directa o de campo, libre o espontánea, dentro del programa institucional Delfín 2020, en el desarrollo de la misma consideramos que se requiere una visión moderna, actual y necesaria para mejorar y optimizar los sistemas de justicia, para ello, brindar una atención inmediata y de prevención de problemas que se puedan agravar con resultados de incremento de violencia y demás, problemas de impacto en la comisión de delitos. Al aportar a la cultura de la paz, la mediación comunitaria se convierte en una herramienta que aboga por la protección de los derechos fundamentales de las comunidades.

Palabras clave: Mediación cultural, Comunidad, Sociedad, Conflicto. 


\section{Abstract}

The purpose of this research is to highlight the importance of community mediation in society, where preserving, ensuring order and social peace are responsibilities of the State closely related to the law, using documentary or indirect methodology, direct or field, free or spontaneous, within the Delfín 2020 institutional program, in its development we consider that a modern, current and necessary vision is required to improve and optimize the justice systems, for this, to provide immediate and preventive care of problems that can be aggravated with results of increased violence and others, problems of impact on the commission of crimes. By contributing to the culture of peace, community mediation becomes a tool that advocates for the protection of the fundamental rights of communities.

Key words: Mediation culture, Community, Society, Conflict.

\section{Introducción}

El mantenimiento del orden y la paz en las sociedades ha sido una de las mayores preocupaciones a través de la historia. Esta angustia fue encaminando a las diferentes civilizaciones a forjarse por medio del establecimiento de normas y regulaciones donde el miedo y el castigo cobran un papel protagónico; constituyéndose dentro del inconsciente colectivo como el recurso más idóneo y eficaz para la conquista de un estado de seguridad que se veía interrumpido por el desorden y el conflicto. No es sorprendente entonces, que tras siglos de aferrarnos a una idea que busca la seguridad en la condena, el reproche, exista en la actualidad una cultura que apunta a las denuncias y que capta la atención institucional, al punto que incluso se vuelve contraproducente para la materialización de la satisfacción de quienes anhelan la tranquilidad.

A su vez, el trance de congestión e impotencia por la que muchos sistemas judiciales están atravesando ha tenido su mayor crisis, contemporánea y coordinadamente, con el desarrollo más lúcido y práctico de un pensamiento que se ha estado originando a partir de diversos acontecimientos en la década de los ochentas, a saber: la cultura de la paz, teoría que no pretende la erradicación del conflicto, (pues reconoce su génesis en la diversidad del individuo, es decir, lo entiende como parte de la condición humana), sino que lo analiza y lo maneja de forma constructiva evitando que escale a niveles de violencia e inseguridad. Este hecho ha generado una importante ampliación del espectro frente a las metodologías que se implementan para el mantenimiento del orden, la seguridad y ha dejado al descubierto la prevención como un factor que puede presentar un gran aporte para la solución de la problemática basados en las demandas actuales de la sociedad, sobre todo a la implementación de modelos que se gesten desde los entornos más próximos a la pluralidad del individuo, como la comunidad.

La preponderancia de la prevención en esta "carrera" trae consigo naturalmente el estudio de mecanismos alternativos como la mediación comunitaria, método, que sí 
bien ya existe, ha sido subvalorado y poco implementado a pesar del gran potencial como catalizador positivo para la creación de verdaderas sociedades en paz, que se detienen en el estudio de las profundas raíces del conflicto, en el repensar de los sistemas actuales de educación y su tendencia creciente por la cultura de la paz.

\section{Breve antecedente histórico jurídico y concepto de mediación comunitaria}

La concepción moderna y genérica de la mediación con tendencias sociales y aún más específicamente el de la mediación comunitaria, no es otra cosa sino una reconstrucción y actualización de un procedimiento antiquísimo que utiliza a un tercero neutral con una alta estimación colectiva para solucionar y/o gestionar el conflicto que suscita naturalmente de las relaciones propias del ser humano. La mediación, más que un invento al que debamos autoría, se debe proclamar hija legítima de los hombres y su decisión de renunciar al íngrimo, aceptando la vida en sociedad junto a lo que ello conlleva; catalogando así, como herencia común de la humanidad. Sería irresponsable endilgar méritos individuales a la existencia de la mediación, por lo menos frente al estado primigenio y general del concepto debido a que muchas sociedades, simultáneamente o no, de forma más o menos rudimentaria, respondieron espontáneamente al desenvolvimiento de los conflictos en sus comunidades a través de la implementación de mecanismos de intermediación o fórmulas similares.

Si no podemos apropiar la mediación a una cultura determinada; menos aún puede ser desligada la interrelación que existe entre esta figura, el progreso de la civilización y el papel que la misma asume frente a un contexto social determinado y sus conflictos específicos, por lo tanto, una aproximación histórica no debe desconocer estos fenómenos que inciden directamente sobre ella misma. De forma acertada (Fernández, 2009) propone a nivel histórico lo que él ha denominado un "itinerario de la mediación social" y justifica el estado actual de la misma en tres etapas: I) la "mediación tradicional" que nace en el seno de comunidades orgánicas tradicionales y se ejemplifica a través de la figura del líder comarcal japones, las propuestas chinas de resolución del conflicto a través de la persuasión moral recopilada por Confucio, las asambleas comunales de África, las cofradías romanas, y no menos importantes, las referencias que hace de las experiencias de latitudes cercanas como los indígenas mapuches en Chile, o en Norteamérica; los organismos de resolución de conflictos propuestos por comunidades europeas migrantes: baptistas, puritanos, cuáqueros o inmigrantes judíos.

Una segunda etapa; II) "medición laboral" con especial énfasis en la resolución de conflictos entre trabajadores y obreros o capital y trabajo, por último; III) una "mediación social" con un panorama de acción más amplio y específico de intervención según el área de trabajo, que se adapta a los cambios sociales; se debe hacer especial énfasis en estas dos últimas etapas, la segunda, porque la mediación en el campo laboral es uno de los antecedentes más directos, consolidados y con mayor respaldo institucional especialmente tras el jueves negro, escenario que nos permitirá evidenciar la influencia 
que ejerció la concepción predominante de lo social en los individuos, en la esfera pública y en diversas áreas de las ciencias sociales sobre la institucionalización de la mediación. La gran depresión se enmarca en el gobierno de Herbert C. Hoover, administración que señala (Gómez, 2014), se basó en los principios del laissez faire postulados que contaban no solo la política y la economía, sino también al ámbito jurídico. Este aspecto, acota; reforzaban el Classical Legal Thought corriente legal imperante en EE.UU hasta los años treinta, situaciones que propiciaron el desencadenamiento de huelgas masivas, violencia y profundos conflictos por parte del gremio trabajador frente al contexto de desigualdad social y laboral. No fue sino hasta 1932 que el panorama empezó a mejorar, cuando Franklin Delano Roosevelt gana las elecciones presidenciales de EEUU y nace el New Deal, movimiento de cambio político, social, filosófico y económico que apalancó la mediación laboral como alternativa para la resolución del conflicto con los gremios trabajadores y que entre otras cosas, propició el surgimiento del realismo jurídico americano, corriente que, a partir de esa experiencia, abogó por los "Alternative Dispute Resolutions" (ADR) y el nacimiento formal de la mediación moderna o social (Gómez, 2014).

Curioso cómo en medio de un contexto totalmente volátil, donde se movían en la escena de una profunda crisis social la violencia y la inseguridad, las nuevas directrices administrativas no se direccionaron a la represión, sino que se sensibilizan ante el contexto social, estableciendo políticas tendientes a la intervención y optaron por retornar y reforzar una idea, que si bien hacía parte de las prácticas comunes, no había sido pensada como una herramienta a niveles de intervención institucional para apaciguar los conflictos provocados por la inconformidad ante un sistema rígido y monopolizado por el liberalismo.

Ahora bien, a través de todo el recuento se ha establecido que: 'La mediación ha existido siempre, sin embargo, su aparición histórica con uniformidad y cohesión, es reciente, data de la década de los años sesenta y setenta y aparece en Estados Unidos" (Pérez Fuentes \& Cobas Cobiella, 2013, p.652-653) " cuando se empezaban a forjar nuevas expectativas en el pensamiento colectivo, naciendo esta figura "dentro del movimiento denominado como ADR" (Fernández, 2009, p.88).

Los años sesenta y setenta se caracterizan por las fuertes contiendas protagonizadas por diversos movimientos para la obtención de nuevos derechos. Precisamente la tutela de esos derechos recientemente adquiridos y el tratamiento legal de los disturbios generados en pro de estas luchas desbordó la capacidad estatal para garantizar justicia, a la par, los "Alternative Dispute Resolution" como procedimientos de carácter extrajudicial que intentaban resolver disputas obtenían relevancia. Esta parte histórica, corresponde a la tercera etapa, "mediación social" momento que permitió establecer que las necesidades derivadas de un conflicto deben tener tratamientos diferenciados en la medida que respondan a contextos disímiles, así; esta institución se empezó a 
decantar y surgieron apelativos para la mediación como: laboral, familiar, comercial y comunitaria y mutó hasta que después de diversas regulaciones se proclamó la "Uniform Mediation Act" o ley de mediación en 2001.

Si bien es cierto, que Estados Unidos es pionero en la mediación, Europa se unió a la apuesta, y a pesar de que la acentuación en el viejo continente fue más paulatina, debido a las rígidas tradiciones jurídicas establecidas, la mediación fue encontrando camino en el Reino Unido, uno de los primeros países en empezar a implementarla, así se fue expandiendo, y hoy; países como España realizan grandes aportes a la doctrina.

Los países de la región americana tampoco fueron ajenos, pero quizá sí un poco tardíos en cuanto a estas implementaciones. México y Colombia optaron por insertar dentro de sus legislaciones, más específicamente dentro de los artículos 17 y 116 de sus constituciones respectivamente los mecanismos alternativos de resolución de conflictos, sin embargo, el ánimo de potencializar estas figuras al punto de elevarlos al rango constitucional se opaca cuando se revisa la vaguedad frente a las regulaciones en la materia. Más bien su teorización, práctica consuetudinaria y reconocimiento como parte del pluralismo jurídico ha favorecido a los aportes para el desarrollo de la mediación.

Hasta ahora, se ha entregado un panorama general de la evolución de la mediación a través de la historia; realizar estas aproximaciones cumple un papel fundamental para perfilar mejor nuestra intención original: resaltar la importancia de la implementación de la mediación comunitaria en las sociedades; es por ello que destinamos la siguiente sección de forma exclusiva al desarrollo y conceptualización de esa categoría de mediación.

Como se había establecido, la década de los setentas en Estados Unidos acento los cimentos para la "clasificación" de la mediación; ello adquiere relevancia en la medida que reforzó la concientización sobre el desarrollo de los conflictos según su ámbito de aplicación, verbigracia; un conflicto que se originaba por el no pago de una deuda no podía recibir el mismo tratamiento que recibe un conflicto que se genera por discriminación racial, ni el mismo que recibiría una persona que sufre afectaciones por comentarios dañinos dentro de su comunidad. Esta distinción, parece de momento superflua, pero representa la evolución del concepto de mediación más allá de un mecanismo que soluciona conflictos de facto; frente a estas categorizaciones algunas perspectivas afirman:

Al atribuir a la mediación el apelativo "social" o "comunitario", se busca hacer distinción de sus prácticas respecto a la denominada "mediación tradicional", que se asume esencialmente como técnica de resolución de problemas. Así, algunos autores afirman que dicha mediación tradicional interviene cuando las tensiones han surgido a niveles de conflicto manifiesto, mientras que la mediación social lo hace también en un estado temprano, es decir, incide sobre una serie de eventos (comenzando por las causas de los conflictos) y reduce la intensidad de aquellos problemas que se manifiestan al trabajar su gestión y transformación, lo cual es algo más comprehensivo que los conceptos tradicionales. (Rincón, 2016). 
En estos términos, un conflicto que se originaba por el incumplimiento de una obligación contractual, uno por discriminación racial, o por comentarios dañinos, no debía recibir el mismo tratamiento. La resolución de estas problemáticas dependerá de su propia naturaleza y del entorno en el que se den, por ejemplo: uno indígena, rural, urbano o uno donde existan o no antecedentes de violencia o que la enfrente en la actualidad.

El proceso de especificación de situaciones, permitió experiencias más concretas dentro de las comunidades. Una de ellas, que podría definirse como "originaria", es el ejercicio de "community mediation" en la ciudad de San Francisco denominada "community boards" propuestas en 1977 por Raymond Shonholtz , la cual; fue producto de años de innovación e improvisación y del nuevo pensamiento que transversaliza el país desde el ascenso de Roosevelt a la presidencia de los Estados Unidos. Esa administración, sumada a la concomitante demora y altos costos de los tribunales se fueron convirtiendo en frustración popular frente al funcionamiento de justicia y llevó a cuestionar la idoneidad y efectividad del proceso judicial para ciertos tipos de disputas (Hedeen, 2004), el escenario posibilitó el repensar jurídico y el auge de los 'Alternative Dispute Resolutions" (ADR), dentro de ellos, el ejercicio planteado por Shonholtz, que consistió en un sistema de resolución de conflictos a través de la mediación comunitaria que tenía por eje central a las personas que hacen parte de una comunidad específica; vecinos de una zona urbana empezaron a practicar intervenciones conjuntas dentro de su entorno y se orientaron principalmente a prácticas de prevención temprana de configuración de conflictos o delitos.

Se puede observar cómo desde el principio los programas que responden a este tipo de mecanismos se visualizaban como recursos para el desarrollo de las capacidades comunitarias, esta categorización de la mediación trascendió a un plano de empoderamiento de las poblaciones y construcción de tejido social. Es por ello, que el concepto de mediación comunitaria hoy en día no solo responderá a una mera provisión de servicios derivados del verbo mediar, sino que los autores han contemplado gran cantidad de posibilidades de injerencia dentro de sus definiciones:

La mediación comunitaria fue adoptada como una herramienta de empoderamiento de individuos y comunidades para recuperar el control de sus vidas que se encontraba en manos de una institución gubernamental (los tribunales) que se consideraba no sólo ineficiente, sino opresiva e injusta (Hedeen and Coy, 2000, como se citó en Hedeen, 2004, p.3)

En el mismo sentido; (Ciappi, 2016, p.267) establece:

Mediación comunitaria, se refiere a aquellas prácticas de intervención que buscan que los miembros de una comunidad se apropien de su capacidad de acción para restablecer las relaciones. La mediación comunitaria puede ser percibida, antes que nada, como un modo de "habilitar" a la comunidad en la gestión de los conflictos sociales y de capacitar a sus miembros para reapropiarse de sus propias vidas, "desarrollando una cohesión comunitaria más fuerte. 
Cabe destacar que dentro del gran abanico de oportunidades que se presentan en los conceptos más actuales de medición comunitaria suelen confluir referencias a la paz, como se puede observar en conceptos propuestos por (Villeda \& Gómez, 2019), en el que establecen la mediación comunitaria no solo como un método alterno respetuoso de los derechos humanos y las garantías individuales, sino que también lo describe como una forma de fomentar la cultura para la paz y el fortalecimiento de los vínculos comunitarios, integración social, sentido de pertenencia y participación ciudadana, siguiendo esta misma línea, Ramírez (2020,p.9), presenta a la mediación comunitaria como: "El instrumento metodológico idóneo para descender a la praxis o realidad social los postulados paradigmáticos del modelo transformador, logrando de esta manera una verdadera pacificación del conflicto."

La "adjetivación" de la noción de mediación comunitaria no es caprichosa, como su historia lo evidencia es una idea social, pero también estatal que se moldea y se vuelve más dinámica conforme nos alejamos de la necesidad de la confrontación adversarial ante tribunales para sentir satisfecho el deseo de acceso a la justicia en determinados casos, se presentan nuevas prácticas de convivencia promocionadas por las gestas de movimientos como la cultura de la paz, y se opta por enfoques de prevención en el escalamiento de los conflictos, generadores de violencia e inseguridad a través de una gestión más adecuada y focalizada.

La importancia de la implementación de la medicación comunitaria en las sociedades radica no solo en que se erigió como una respuesta rápida y eficiente a diferentes problemáticas que se han presentado, sino también porque se ha mantenido vigente a través del tiempo moldeando con cada nuevo paradigma y concepción de fenómenos como el conflicto. El concatenamiento de factores que inciden en la suma del componente histórico y conceptual servirán para establecer de forma más clara los aportes de la mediación comunitaria a las sociedades. En este punto, podemos identificar con más facilidad la importancia de la implementación comunitaria conforme a su desarrollo en la historia: la primera de necesidad, que se deriva del afán por encontrar mecanismos que garantizaran el acceso a la justicia y colaboraran con el descongestionamiento judicial, una segunda etapa transición y especificación del concepto de "mediación genérica" a la "mediación comunitaria" y su influencia frente al reforzamiento de entender las necesidades que suscitan en un entorno determinado, evidenciando las potencialidades de la figura frente al empoderamiento ciudadano; y una tercera etapa de transversalización, donde entra el juego la manera como irradia la cultura de la paz y va calando en el pensamiento colectivo para, consecuentemente influir en la figura de la mediación comunitaria promoviendo la construcción de sociedades pacíficas.

Es preciso entonces identificar las características más importantes de cada una de estas etapas con el fin de evidenciar los aportes y retos de cada uno de esos estadios. 
La mediación comunitaria: una figura que deambula en medio de la justicia formal e informal

La mediación comunitaria tiene como una de sus fuentes a los denominados mecanismos alternativos de resolución de conflictos, los cuales se traducen en un tipo de movimiento social que en primera instancia buscaba responder a la latente necesidad de garantizar el acceso a la justicia generado por el colapso de los sistemas tradicionales de forma tal que los implicados propiciarán formas de solucionar sus problemáticas, propendiendo por la "desjudicialización de la solución de conflictos", tal situación empieza a profundizar cada vez más y las personas empiezan a basar la idea de acceder a la justicia bajo un supuesto de: "Desconfianza frente a la justicia formal del Estado puesto que no la consideran un instrumento eficaz, transparente y adecuada para zanjar las controversias cotidianas de los ciudadanos" (Uprimny, 2005, p.1). Si bien es cierto, que este tipo de mediación se desenvuelve preponderantemente en un sistema informal de impartición de justicia, se deben tener en cuenta los aportes que podría traer consigo un apoyo más consolidado desde el aparato estatal, ya sea desde los órganos administrativos o judiciales de los países, de igual manera, se deben empezar a cuestionar cómo funcionan las potestades judiciales que se brindan temporalmente para la administración de justicia y si ello, resulta beneficioso o no para este tipo de metodologías.

Podría pensarse que la mediación comunitaria como mecanismo alternativo de resolución de conflictos se enmarque dentro del amplio concepto de justicia, como una informal y evidentemente comunitaria, suponiendo entonces que se encuentra clasificada en la otra orilla de los sistemas de justicia formales, no obstante, esto es relativo y consideramos puede ser una apreciación que se aleja en parte de la realidad; contrario a quienes afirmaron que las dos están aisladas, planteamos que mecanismos como la mediación comunitaria deben ser un complemento al sistema estatal y formal de justicia y que incluso en ocasiones pertenecen a la formalidad, pues puede originarse las facultades excepcionales que otorga el Estado para la administración de justicia por medio de su regulación legal.

¿Por qué la justicia informal empieza a adquirir un papel tan importante para lograr obtener el acceso a la justicia? frente a esta pregunta, compartimos los argumentos esbozados por Uprimny (2005), referentes a la propia incapacidad de la justicia formal de tramitar satisfactoriamente ciertos asuntos, existen tres, formulados por categorías: i) obstáculos e impedimentos de entrada ii) disfuncionalidades del aparato judicial y iii) distorsiones de la política social. Estos factores, menciona el autor; obstaculizan la resolución de conflictos por medio de trabas económicas, especialmente cuando los conflictos son de baja cuantía, haciendo perder el interés de las partes, debido a que los costos judiciales son exorbitantes. En igual sentido, confluyen factores de tipo espacial, debido a que se debe estar presente en diversas actuaciones o diligencias que requieren los procesos, o hay que realizar desplazamientos a sitios donde se encuentre ubicados los tribunales. También hay barreras temporales en cuanto a la resolución rápida de 
los conflictos que se ven inmersas en tramites procesales de mucho conflicto. A todos ellos, se suman las barreras educativas y de asesoría técnica donde el desconocimiento se ve recrudecido cuando la impartición de justicia va dirigido a sectores vulnerables y empobrecidos.

En la siguiente gráfica, se pueden apreciar los principales factores que demuestran la incapacidad de la justicia formal en el tramite de ciertos asuntos según Uprimmy:

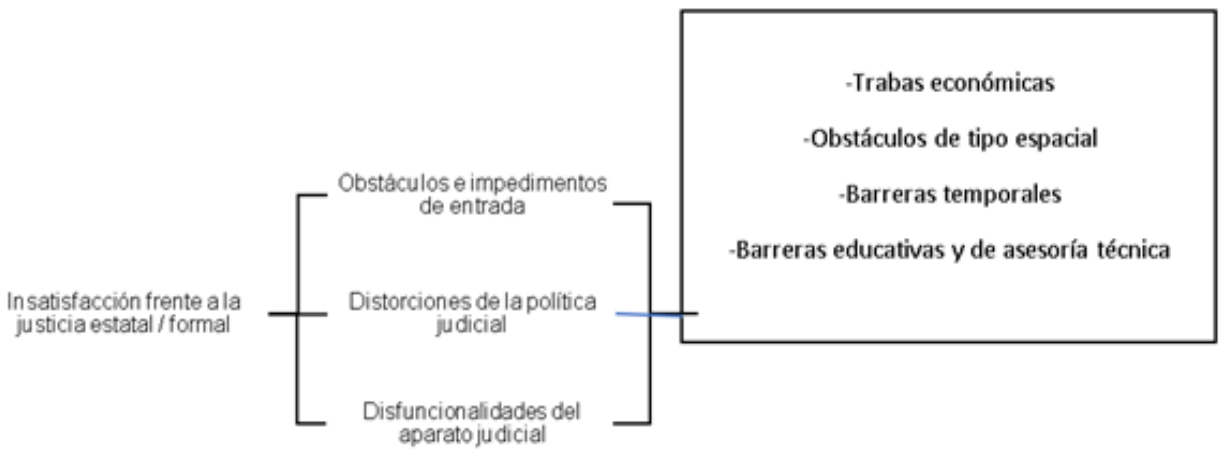

Fuente: los autores, creación propia.

La mediación comunitaria, como parte del conjunto de la justicia informal juega un papel importante para el acceso a la justicia, y para la descongestión judicial en la medida que podrían decepcionar causas que por sus características particulares se podrían solucionar en instancias de consenso. No obstante, la justicia informal trae consigo riesgos que no deben pasar desapercibidos y se deben considerar:

Resultados injustos legitimados, sobre todo cuando hay desigualdad entre las partes o terceros que pueden verse afectados no son vinculados a la negociación, tiranías originadas por la confusión de la autoridad estatal y sancionatoria con la comunitaria, simplificación de luchas sociales, descargas que tiene el estado de brindar justicia discriminando una justicia de primera para quien puede obtenerla y una justicia de segunda para pobres y marginados. (Uprimny, 2005, p.8)

Es por tanto que la universalidad de la justicia debe enmarcarse en una vigilancia que puede ser estatal, pero que irremediablemente también debe tener en cuenta a la ciudadanía, por lo tanto, va a requerir de niveles de formación de las personas que impartan este tipo de justicia y que estén avalados por las comunidades, de acuerdo con ello, se debe hacer énfasis en que se propugna por las capacitaciones y se dote de herramientas a las comunidades para poder realizar una mejora continua de este mecanismo. 


\section{La mediación comunitaria como justicia formal}

La mediación comunitaria como justicia formal es un tema que no se ha estudiado en profundidad y que puede llegar a presentar diversas preguntas, no obstante, se pone de presente y se puede establecer la posibilidad que se deriva de potestades que están expresamente reguladas en las codificaciones de los diferentes países, se va presentando a su vez como una manera de crear e idear políticas sociales. En el caso colombiano, por ejemplo, existe una facultad de administrar justicia de manera excepcional, está establecido en el párrafo 3 del artículo 116 de la Constitución Política de Colombia en los siguientes términos: 'Excepcionalmente la ley podrá atribuir función jurisdiccional en materias precisas a determinadas autoridades administrativas, sin embargo, no les será permitido adelantar la instrucción de sumarios ni juzgar delitos" inmediatamente después, en el párrafo 4 se señala : 'Los particulares pueden ser investidos transitoriamente de la función de administrar justicia en las condiciones de jurados en las causas criminales, conciliadores, en la de árbitros habilitados por las partes para proferir fallos en derecho en equidad, en los términos que determine la ley" si bien es cierto que no se menciona la mediación, el párrafo 3 establece que en materias precisas, a determinadas autoridades administrativas se le atribuye la función jurisdiccional. Cabe resaltar, figuras que existen en el marco legal colombiano como los inspectores de policía, cargos creados desde la administración, que entre muchas funciones se encargan de regular situaciones en materia de convivencia en municipios, y guían parte de su actuar por medio de la Ley 1801 de 2016 o Código Nacional de Seguridad y Convivencia Ciudadana. Esta normatividad contempla en su artículo 333 la posibilidad de la mediación así: "La mediación permite que el mediador escuche a las personas que se encuentran en situación de conflicto, convivencia y facilita un camino para encontrar una solución equitativa. De realizarse el acuerdo, se suscribió acta de mediación, donde se consignarán las obligaciones a cargo de cada uno de los interesados, la cual hará tránsito a cosa juzgada y prestará mérito ejecutivo" las mediaciones que realizan estas figuras normalmente pueden ser por conflictos que respondan a la convivencia entre ciudadanos, incluyendo entre ellos problemas entre vecinos, problemáticas por una mala tenencia de animales, etc.

Las preguntas que podrían surgir son: ¿El inspector de policía realiza mediación comunitaria? Y la otra ¿El inspector de policía en este caso está administrando justicia de manera excepcional bajo potestades extraordinarias? La respuesta a la primera pregunta es clara, sí ejerce mediación comunitaria, incluso, el título que detenta "'Inspector de Policía" sea cual sea la persona designada en el cargo (que normalmente debe ser un titulado en derecho), en muchas ocasiones representa para la comunidad, especialmente en zonas rurales "la ley", es por ello, que se configuraría también la legitimidad simbólica de un mediador comunitario, pero que en este caso se enmarca dentro de una institución administrada por el Estado. 
La segunda tiene más dificultades, exegéticamente la respuesta tendería al no, pero podría cuestionarse, ya que no existe pronunciamiento frente a este tipo de casos, sin embargo, es importante repensar este tipo de figuras, para lograr blindar de mayor seguridad jurídica a este tipo de prácticas y sus decisiones, más allá de los efectos que ya se otorgan en el mismo articulado, pues representa decisiones importantes y con mucho valor para las personas que acuden a esta institución, teniendo en cuenta sobre todo que, los inspectores o corregidores suelen encontrarse en municipios o zonas rurales, donde el andamiaje judicial es precario o no puede cubrir todos las conflictividades que se suscitan, especialmente en entornos tan diversos como el colombiano.

Bajo estas dos lecturas quedan grandes interrogantes, existe un claro aporte de la mediación comunitaria, pero ¿Dónde debe enmarcarse para que funcione de la mejor manera: en la justicia informal o en la formal? esta sin duda es una pregunta con una respuesta riesgosa. Per se, debería ser un mecanismo exclusivamente de la justicia informal, de la ciudadanía para la ciudadanía, no obstante, ello implicaría la necesidad de que los estados implementaran programas de capacitación, no solo para los funcionarios públicos, sino para las personas del entorno que evidencian capacidades de mediación, sensibilidad social y conocimientos sobre las problemáticas de convivencia dentro de su comunidad, es decir, que necesitaría un apoyo institucional.

Es claro que existe la posibilidad de que se enmarque un tipo de mediación comunitaria formal en una entidad que está facultada legalmente, y en el mismo sentido que este instrumento metodológico también se presenta para los sistemas judiciales, como una posibilidad de descongestión judicial interesante, pero se debe tener en cuenta que no se debe rezagar a la mediación comunitaria como un simple complemento a la justicia ordinaria y formal, o a la mera asistencia jurídica, ya que ello conlleva a desconocer los avances y potencialidades que ha obtenido con el tiempo para mejorar el diálogo, la participación y el repensar de la convivencia social. Menos aún podría homogeneizar el ejercicio de esta práctica con la rigurosidad de la justicia formal, a pesar de que sí se deben tener en cuenta partes y fases que pueden ser comunes de experiencias que ya se han tenido, establecer un procedimiento específico y general podría perder la esencia de uno de los elementos más importantes de la mediación comunitaria: el contexto; ello significa que se asume una concepción tradicional y subsidiaria de la misma, otorgándole un carácter servil ante la justicia ordinaria como un medio para la descongestión, obviando factores exógenos que repercuten al momento de detectar conflictos y problemas generalizados en una sociedad y poder implementar las formas de trabajar sobre las causas de los mismos, como la política, la economía y la cultura, impidiendo la comunicación de actores territoriales y limitando la búsqueda conjunta de soluciones respecto a la seguridad y la violencia. 


\section{Elementos especiales y comunes para la implementación de la mediación comunitaria}

El papel fundamental del contexto en la evolución y la implementación de la mediación comunitaria

La mediación comunitaria ha tenido una gran acogida en el mundo, pero es innegable que su práctica y evolución normativa en cada país varia. Los contextos y necesidades de cada región y población son diferentes. El desarrollo de esta figura en países que hemos observado con anterioridad como Estados Unidos o España, por ejemplo, que pueden tener mejores estándares de calidad de vida e índices democráticos más altos, van a tender a implementarse en esferas vecinales, mayoritariamente urbanas, y van a direccionarse a empoderar a las comunidades para luchar y solucionar problemas relacionados con conflictos entre vecinos por mal uso del espacio común, contaminación auditiva, robos menores, vandalismo y en la actualidad han empezado a abarcar espacios interculturales derivados de los fenómenos migratorios, evidencia de ello las experiencias de: "El ayuntamiento de Vitoria que ofrece servicios en mediación vecinal, el ayuntamiento de Madrid donde que realiza mediación vecinal intercultural" (Soleto Muñoz, 2007, p.9) y también pronunciamientos en el boletín oficial del estado de legislación consolidada de la comunidad Autónoma de Cataluña sobre la Ley 15/2009, de 22 de julio de medición en el ámbito del derecho privado:

La llamada mediación comunitaria, social o ciudadana se ha revelado muy útil para resolver problemas caracterizados por el hecho de que las personas involucradas deben continuar relacionándose. Son ejemplos evidentes los conflictos derivados de compartir un espacio común y las relaciones de vecindad profesionales, asociativas, colegiales o, incluso, del ámbito de la pequeña empresa. (pág.5)

Por supuesto que en cada uno de los ejemplos anteriores existe un carácter social, pero las tendencias legislativas, manejo institucional y prácticas consuetudinarias de implementación van a resultar diferentes de países en etapas más tempranas de desarrollo, con índices democráticos y de calidad de vida más bajos, que se encuadran en contextos de miedo constante y un pensamiento predominantemente violento, que se derivan de conflictos armados, problemas de narcotráfico, entre otros, se puede visualizar una tendencia que Ileva a apreciar aún más el carácter social de este mecanismo, ligándolo con más fuerza a la protección de derechos humanos y la construcción de paz, encontrando una oportunidad para aplicar la mediación comunitaria en contextos diversos y de cierta forma, explotando aún más este mecanismo y haciendo su uso más extensivo.

Podemos referirnos en este sentido nuevamente a casos como el colombiano, ecuatoriano y mexicano. En el caso colombiano la medición comunitaria ha aparecido constantemente en espacios relacionados con escenarios de recuperación de tejido social, acompañando procesos de desmovilizaciones de grupos armados y recuperación de territorios afectados por la violencia de los mismos. La lectura de Eslava Rincón, 
demuestra que tras la ejecución de la estrategia nacional contra la violencia implementada en 1992 por el gobierno, debido a las condiciones críticas de finales de los ochenta y comienzos de los noventa producidas por el auge del narcotráfico, la violencia política y dinámicas de violencia más generalizadas, se empezaron a gestar procesos de formación a ciudadanos, especialmente, en mediación comunitaria, paralelas al proceso de negociación con grupos al margen de la ley en Medellín. Señala la autora también que las formaciones siguieron extendiéndose en esta ciudad y en Bello, entre los años 2001 y 2003 a través de diplomados con contextos amplios de derechos humanos y cultura de la paz.

Por otro lado, el caso ecuatoriano ha implementado dentro de su legislación de forma específica la medición comunitaria, en el título III, de la Ley de Arbitraje y Mediación artículos 58 y 59 :

"Art 58: Se reconoce la mediación comunitaria como un mecanismo alternativo a la solución de conflictos.

Art 59: Las comunidades indígenas y negras, las organizaciones barriales y en general las organizaciones comunitarias podrán establecer centros de medición para sus miembros, con carácter gratuito, de conformidad con las normas de la presente ley (...) Los centros de medición, de acuerdo a las normas de esta ley, podrán ofrecer servicios de capacitación apropiados a los mediadores comunitarios, considerando las peculiaridades socio-económicas, culturales y antropológicas de las comunidades atendidas " (subrayado fuera de texto).

Obsérvese cómo en un país donde: 'La población indígena se acerca a 1,1 millón, por sobre una población total que supera los 17.300.000 habitantes" (Mamo, 2020, p.409) se propone de manera certera la mención de las comunidades indígenas, lo que conlleva también al reconocimiento implícito de la cosmovisión que cada una pueda tener y la necesidad de asumirlo en la mediación comunitaria en consonancia con el artículo 171 de la Constitución del mencionado país.

Para el caso mexicano por su parte, se tiene el antecedente que en el año de 1997 se inicia la práctica de los métodos alternos de solución de controversias en el Estado de Quintana Roo, donde crearon un centro de asistencia jurídica, como un órgano desconcentrado del poder judicial, donde el objetivo fundamental era que los particulares resolvieran sus controversias jurídicas de carácter privado, iniciativa, y ejemplo que otras entidades federativas replicaron, por lo que le siguió el Estado de Guanajuato, reformando su Constitución Estatal ya en los años 2003 e inclusive publicando la primera Ley de Justicia Alternativa en el interior del país, la cual regula los procedimiento de mediación y conciliación para con ello volverse un referente en el tema a nivel nacional, ya que posteriormente crearon un Centro de Justicia Alternativa con 5 sedes en el interior del Estado. 
En ocasión al avance en el desarrollo de los mecanismos alternativos de solución de conflictos, la reforma constitucional del 2008, trajo consigo, entre otros, un nuevo párrafo al artículo 17 del texto constitucional México, relevante para el tema que nos ocupa y que refiere lo siguiente: " Las leyes preverán mecanismos alternativos de solución de controversias. En la materia penal regularán su aplicación, asegurarán la reparación del daño y establecerán los casos en los que se requerirá supervisión judicial" (Honorable Consejo de la Unión [HCU] DOF 18/06/2008, p.1). Posteriormente, en el 2017, nuevamente se añadiría a este mismo artículo del texto supremo legal de México el párrafo: "Siempre que no se afecte la igualdad entre las partes, el debido proceso u otros derechos en los juicios o procedimientos seguidos en forma de juicio, las autoridades deberán privilegiar la solución del conflicto sobre los formalismos procedimentales." (HCU, DOF 15/09/2017, p.1)

De igual manera, en relación con el tema central de la medicación comunitaria solo algunas entidades federativas la prevén y utilizan, como el Estado de Nuevo León, por lo que falta una cultura de ajuste, donde prevalezca el costo-beneficio de la aplicación y vigencia, aunque se generan estudios de análisis de la figura.

Así, debe resaltarse la importancia de asumir el contexto donde se va a implementar el mecanismo, la evidencia va mostrando cómo países con situaciones concretas, enmarcados en contextos volátiles, o donde confluye gran diversidad de comunidades que comparten un mismo espacio, no solamente vecinal urbana o de inmigrantes, sino también campesina, indígena, raizal o víctimas de desplazamiento forzado, y en donde se acentúan aún más las problemáticas por los factores geográficos, de vulnerabilidad y pobreza, requieren de especial atención, pues esas situaciones van a influir indefectiblemente en la evolución y progreso de la medición comunitaria.

\section{Elementos comunes de la mediación comunitaria en cualquier contexto}

A pesar de que existen elementos en la mediación comunitaria como el contexto que requieren ser tratados con sumo cuidado, hay otros elementos que si bien tienen un carácter supremamente importante que los distingue de la mediación general, funcionan para detectar en qué momento se están llevando a cabo procedimientos que pueden responder a ejercicios de mediación comunitaria.

Una comunidad: Esta va a responder a un grupo de individuos que se enmarca en un contexto específico determinado, ya sea porque comparten una zona geográfica determinada, un espacio, intereses políticos, culturales, económicos o, de manera general, sociales.

Mediador: Un tercero imparcial que debe poseer ciertas características especiales. Gran importancia revestirá que tenga un conocimiento profundo sobre la comunidad donde va a ejercer la mediación, deberá comprender y conocer los códigos y el universo simbólico de la misma. 
Situación específica conflictiva: Esta se da en el entorno social y deben responder a situaciones que no sean gravosas y que según la ley vigente tengan la posibilidad de resolverse a través de la mediación.

\section{La transversalización de la cultura de la paz en el desarrollo de la noción del conflicto y sus aportes a la mediación comunitaria}

La génesis del concepto genérico de la mediación se da a partir de la existencia per se de los conflictos, no obstante; la percepción que las sociedades asuman frente al conflicto, también, será un factor determinante en el desenvolvimiento de la mediación comunitaria; si bien es cierto, que los primeros ejercicios comunitarios visualizaron los potenciales de esta figura, las posturas que ha asumido la cultura de la paz frente al conflicto y su transversalización en el imaginario social han influenciado aún más en el auge de la implementación de la mediación comunitaria, si bien es cierto, que la cultura de la paz es un movimiento que se empieza gestar:

En el siglo XX, después de la firma de las paces que pusieron fin a las guerras mundiales, cuando se comenzó a tomar conciencia de la importancia de que fuese reconocida con todo su potencial como un instrumento de gestión y transformación de las entidades humanas (Muñoz \& Rueda, 2010).

No fue sino con la difusión de Unesco a partir de 1989, especialmente en 1997 con la Resolución de 20 de noviembre en la que se proclama el 2000 como año Internacional de la Cultura de la Paz, en 1998 cuando se concibe al periodo del 2001-2010, como Decenio Internacional de una cultura de paz y no violencia para los niños del mundo y en 1999, con la Declaración y Programa de Acción sobre una Cultura de Paz que su materialización y desarrollo empezó a ser más creciente en los países, por ejemplo:

La iniciativa Manifiesto 2000 de la Organización de las Naciones Unidas para la Educación, la Ciencia y la Cultura, pretendía motivar hacia una cultura de la Paz. El Manifiesto se tradujo a más de 50 idiomas, lo firmaron numerosos Jefes de Estado y de Gobierno y se difundió en todo el mundo. También se invitó a todos los ciudadanos a que lo firmaran comprometiéndose a practicar sus principios en la vida diaria. Al finalizar el año 2000 se contabilizaron más de 74 millones de firmas procedentes de todo el mundo, más del 1\% de la población mundial(Labrador Herráiz, 2003).

Quizás uno de los documentos que nos entrega una definición más clara de la cultura de la paz en relación con el reconocimiento del conflicto, es la A/RES/53/243 o Declaración y Programa de acción sobre una Cultura de la Paz, expedido por la Asamblea General de las Naciones Unidas y que señala en su preámbulo:

Reconociendo que la paz no sólo es la ausencia de conflictos, sino que también requiere un proceso positivo, dinámico y participativo en que se promueva el diálogo y se solucionen los conflictos en un espíritu de entendimiento y cooperación mutuos. Resolución 53/243 Asamblea General "Declaración y programa de acción sobre una Cultura de la Paz" A/RES/53/243 (6 de octubre de 1999). 
La cultura de la paz entonces, podría asumirse; reconoce que la misma se puede dar en el marco de los conflictos y no propugna por la erradicación del conflicto, si no que lo considera inherente al ser humano y necesario para las reivindicaciones a través del fortalecimiento del escepticismo y la creatividad. Lo que sí clarifica, es que no se puede dejar sin tratamiento el conflicto y que los mismos se deben solucionar a través procesos positivos, de lo contrario, podría representarse a través de una línea recta, donde el conflicto asciende directamente a violencia, y que con la acentuación de los mismos, termina deformándose, difuminando su principio y fin y convirtiéndose en un círculo vicioso y destructivo; como ya se había comprobado, con la reciente experiencia de la culminación de la Guerra fría en 1991, situación de tensión, que también influyó en la concreción de la resolución, como se da por sentado cuando se manifiesta: "Reconociendo también que el final de la guerra fría ha ampliado las posibilidades de reforzar una cultura de paz". Resolución 53/243 Asamblea General "Declaración y programa de acción sobre una Cultura de la Paz" A/RES/53/243 (6 de octubre de 1999).

Empezar a asumir la inherencia propia del conflicto a la sociedad y encontrar en él incluso oportunidades para el cambio, concientiza sobre la necesidad de buscar mecanismos que colaboren en la gestión del conflicto de forma amplia y propendan por un cambio en la forma en que las personas asumen sus relaciones con los demás. ¿Por qué la mediación comunitaria salta a la vista como una candidata fuerte para asumir esta ardua labor?, como menciona (Ríos, 2015), el factor más importante en una sociedad es el conglomerado humano, y la base de su desarrollo responde a las expectativas de vida o de su entorno social, económico y político, así las cosas, las comunidades ${ }^{1}$ como entornos más próximos que tiene un individuo para exteriorizar su forma de interactuar socialmente después de la familia y siendo el ejercicio más cercano para aprender a convivir, y a su vez, una fuerte influencia sobre la percepción de las realidades, y por tanto; el manejo de sus conductas y comportamientos se presenta como uno de los lugares más idóneos donde se pueden realizar intervenciones que generan transformaciones sociales reales, pues tiene grandes bondades en lo que respecta a la creación de culturas democráticas a través de la participación ciudadana, empoderamiento y reforzamiento del reconocimiento. Esta trinidad va a ser el punto de partida de una reflexión política sobre la intervención de diversos actores privados, públicos, civiles e institucionales como promotores de sociedades pacíficas donde se garantizan a través de nuevas prácticas la seguridad y la disminución de la violencia por medio de políticas de prevención.

La mediación comunitaria específicamente como forma de construcción de paz

Se ha propuesto a la mediación comunitaria como un instrumento metodológico idóneo que logra crear verdaderas transformaciones y que intenta desarrollar la vida de los seres

1. Vamos a hablar de qué se entiende por comunidad cuando hablamos de mediación comunitaria. 
humanos en sociedades pacíficas, precisamente porque entienden la comunidad como el lugar donde entran en tensión la persona como individuo y el convivir en sociedad de manera más próxima. Podría insinuarse que confluyen en un mismo espacio geográfico la autonomía individual y la solidaridad, los intereses individuales propios, los de otro y los generales, la comunidad se visualiza como una oportunidad de construcción donde confluyen un proyecto de vida individual y la persecución de intereses colectivos haciéndolo un nicho propicio para crear conciencia y transformar realidades. Con referencia a la mediación comunitaria frente al desarrollo de la cultura de la paz, autores como Alzate Sáez De Heredia et al., (2013), siguiendo el modelo anidado del conflicto de Dugan y su aplicación para construcción de la paz por Lederach, proponen que conforme a la existencia de cuatro tipos de conflictos que se interrelacionan:

a) Personal: Normalmente son problemas concretos, ocurren entre individuos 0 grupos, pero que no son la causa del conflicto.

b) Relacional: Suceden por patrones de interacción y la percepción o sentimientos que tenemos sobre los demás.

c) Estructural o de las estructuras subsistencias: Son procedimientos y reglas de la organización social particular es donde la cultura se refleja.

d) Sistema social o cultural: Aquellos que van más allá de las relaciones y están institucionalizados.

El papel de la mediación comunitaria, señalan los autores; toma protagonismo en los tres primeros niveles de conflicto, jugando un rol intervencionista, es decir que incide de manera directa sobre ellos; en el último nivel va a actuar como influencia de forma indirecta y con los trabajos realizados en los tres primeros niveles que no se van a reducir exclusivamente al servicio de medición, sino que por lo general comprenden otros procedimientos como la formación de resolución de conflictos, facilitación de reuniones, construcción de consensos, o incluso la participación en la medición de políticas públicas, asumiendo de forma general un modelo transformativo de medición que ya ha sido bosquejado por Bush y Folger en "The promise of mediation" y que se basa en el empoderamiento (sentimiento de autosuficiencia), fortalecimiento (en el control de materias que le afectan) y reconocimiento (voluntariedad de mostrarse más empáticas).

Es así como la medición comunitaria y la cultura de la paz son dos estrategias con gran sinergia que de trabajar de forma mancomunada, lograrán poner de presente una nueva oportunidad para redireccionar las apuestas de los gobiernos por una mejor convivencia, generando en ellas paz social, armonía y una sana convivencia. 


\section{La mediación comunitaria como forma de prevención}

Habiendo relacionado a la mediación comunitaria con la construcción de sociedades pacíficas es imposible no referirse a la relación que esta tiene con la prevención de la comisión de delitos. Para hacer mención a este tema, es importante, aunque sea de manera muy somera, exponer algunas razones por las cuales un individuo podría a llegar a cometer un delito en el ámbito comunitario o en las relaciones que se derivan de esa interacción tan propia. No podría suponer el lector que fueran las únicas, pues es un tema supremamente amplio que ha requerido grandes volúmenes de enciclopedias penales e incluso de áreas como la psicología para su comprensión; pretendemos más bien, evidenciar que el método transformativo que hemos enunciado permite prevenir conductas delictivas o escalonamiento de violencia al punto que se tipifiquen en delitos graves, bien sea porque antecede a la concreción de factores como exclusión social, vulnerabilidad, pobreza, desigualdad que pueden desencadenarse a través de la búsqueda de justicia social que hemos podido observar al caracterizar a la figura ampliamente durante el texto.

O en palabras de Ciappi, (2016) porque:

'Una gran ventaja de los enfoques comunitarios es que buscan operar dentro del ámbito de las relaciones interpersonales y colectivas. Si se tiene en cuenta que, como demuestran las investigaciones criminológicas, gran parte de la violencia y de los abusos que suscitan alarma social y miedo ocurren dentro de relaciones ya estructuradas (entre familiares, socios de negocios, vecinos de casa, exparejas, entre otros)' (pág. 219).

En el mismo sentido, refiere esta autora ligando el carácter preventivo a la inoperancia de instrumentos jurídicos penales que solo los ciudadanos podrían tomar conciencia de las fases iniciales, de los conflictos impidiendo el delito con ayuda del mediador y que aquella naturaleza de la mediación comunitaria fue analizada premonitoriamente por uno de sus padres, Raymon Shonholtz (1984) afirmaba:

Cualquier otra política de intervención deja que los conflictos y los desequilibrios degeneren hasta la intervención del sistema jurídico, que se da tras el hecho y que deja a la víctima ofendida o afectada como testigo de la inexistencia de la prevención en el sistema de derecho (Ciappi, 2016, pág. 218).

Las aspiraciones pacificadoras de la mediación comunitaria y su lucha por la creación de foros de diálogo y debate respetuoso de diferentes actores territoriales y comunitarios en espacios que parecen desfavorables por medio de la participación en la solución de conflictos, de la proposición de mecanismos y políticas públicas pueden crear personas con tendencias a nuevas solidaridades, y crearán espacios de seguridad renovados, según (Silva, 2010): 'La participación activa en la comunidad, es una idea importante para la estructuración y el desarrollo de las actividades de seguridad',' (Sani \& Nunes, 2016, pág. 1). Esto evitará la creación de atmósferas para el delito, ya que como se ha 
podido dilucidar el espectro de posibilidades de la mediación comunitaria abarca también, temas relacionados con el desarrollo de los derechos humanos y la progresividad de derechos económicos, sociales, culturales y de medio ambiente, es claro, que estas son alternativas que requieren de pensamientos a largo plazo y de forma progresiva, no obstante, ya hay un gran camino recorrido y las bases se encuentran sentadas para mejorar su implementación.

\section{Conclusiones}

La mediación comunitaria es una herramienta que permite a las comunidades la construcción de entornos pacíficos por medio de la caracterización de su contexto específico, del diálogo y la participación de todos los actores que inmersos en ellas, aumentando así las posibilidades de materializar transformaciones reales debido a que propicia el empoderamiento, el fortalecimiento y el reconocimiento de los y entre los individuos que la conforman.

El fomento de comunidades pacíficas por medio de la mediación comunitaria influye en el aumento de percepción de la seguridad y previene la configuración de conductas delictivas, pues antecede la concreción de factores que propician las mismas.

La transversalización de la cultura de la paz y su influencia sobre la noción del conflicto en el imaginario colectivo de los seres humanos, apalancó el auge de la mediación comunitaria como una herramienta de las comunidades, alejándose de los conceptos tradicionales de la justicia formal que más allá de reconocer sus potencialidades, la reducían a una figura subsidiaria para la mera descongestión judicial.

Al aportar a la cultura de la paz, la mediación comunitaria se convierte en una herramienta que aboga por la protección de los derechos fundamentales de las comunidades.

\section{Propuestas}

La mediación comunitaria tiene que considerarse con más seriedad por parte de los gobiernos nacionales y locales, si bien es cierto, que es una herramienta que pertenece a la ciudadanía, es necesario que sea apoyada por los entes estatales con inversiones y capacitaciones, para que sea correctamente implementada y no degenere en una manera de minimizar causas o corromper aún más la justicia.

Se debe empezar a repensar en cómo debe ser aplicada la mediación comunitaria sin que pierda su esencia, es necesario que las legislaciones asuman el reto de su codificación y sistematización, sin perder de vista que los actores principales son las comunidades y los contextos, por ello, se debe manejar un rango de flexibilidad de la figura, sin caer en el error de que se vuelva un proceso rígido y de difícil acceso. 
Se deben empezar a implementar más ejercicios de mediación comunitaria, creando "laboratorios" de ejercicios de mediación específica en zonas de alto impacto, realizando previamente estudios y diagnósticos de las zonas donde serán aplicados.

\section{Bibliografía}

Alzate Sáez De Heredia, R., Fernández Villanueva, I., \& Merino Ortiz, C. (2013). Desarrollo de la cultura de la paz y la convivencia en el ámbito municipal: La mediación comunitaria. Política y Sociedad, 50(1), 179-193. https://doi.org/10.5209/rev_ POSO.2013.v50.n1.39350.

Ciappi, S. (2016). Las primeras experiencias de mediación social. In J. I. E. Rincón (Ed.), Mediación social, teorías y enfoques de intervención (1st ed., pp. 218-219). https:// repository.javeriana.edu.co/handle/10554/41017

Erazo, P. E. R. (2015) “ “ La Mediación Comunitaria Realizada Por Los Promotores Indígenas De Derechos Humanos En Las Comunidades Pertenecientes a La Unorcac ." http:// www.dspace.uce.edu.ec/handle/25000/6338.

Fernández, S. (2009). La mediación social: itinerario histórico resolución de conflictos sociales . La Razón Histórica, 77-97. https://digitum.um.es/digitum/ bitstream/10201/43767/3/Sergio Fernández Riquelme. La Mediación social. La Razón histórica 9\%2C 2009.pdf.

Gómez, C. M. (2014). Origen y evolución de la mediación: el nacimiento del «movimiento ADR» en Estados Unidos y su expansión a Europa. Anuario de Derecho Civil, Tomo LXVII, 931 a 996. https://dialnet.unirioja.es/servlet/articulo?codigo $=4824884$

Hedeen, T. (2004). The evolution and evaluation of community mediation: Limited research suggests unlimited progress. Conflict Resolution Quarterly, 22(1-2), 101-133. https://doi.org/10.1002/crq.94.

Labrador Herráiz, M. (2003). La cultura de la paz, marco para la ciudadanía. Revista de Educación, 1, 155-168. https://dialnet.unirioja.es/servlet/ articulo?codigo $=761199$.

Mamo, D. (2020). El mundo indígena 2020. http://iwgia.org/images/yearbook/2020/ IWGIA_EI_Mundo_Indigena_2020.pdf

Miranda Pinto, N. (2016). Gestión de conflictos en la comunidad y la mediación Comunitaria como vía alternativa de resolución. 1-63. https://riull.ull.es/xmlui/ bitstream/handle/915/3818/Gestion\%20de\%20conflictos\%20en\%20la\%20 comunidad\%20y\%20la\%20Mediacion\%20Comunitaria\%20como\%20via\%20 alternativa\%20de\%20resolucion..pdf?sequence=1\&isAllowed=y 
Muñoz, F. A., \& Rueda, B. M. (2010). Una cultura de Paz compleja y conflictiva. La búsqueda de equilibrios dinámicos. Revista de Paz y Conflictos, 3(1), 44-61. https://doi.org/10.30827/revpaz.v3i0.441.

Pérez Fuentes, G. M., \& Cobas Cobiella, M. E. (2013). Mediación y jurisdicción voluntaria en el marco de la modernización de la justicia. Una aproximación a la legislación Española. Boletín Mexicano de Derecho Comparado, 46(137), 647-677. https:// doi.org/10.1016/s0041-8633(13)71145-1.

Ramírez,G.S.(2020).Implementacióndelamediacióncomunitariacomovíadepacificación de los conflictos. (Vol. 03, pp. 67-80). https://www.estudiosdepazyconflictos.com/ index.php/eirene/article/view/82.

Ríos, G. Á. J. (2015). Modelo de gestión organizacional para los procesos de mediación comunitaria enmarcado en el bien vivir de los habitantes del barrio 16 de Julio del Cantón Santa Elena, año 2014-2015”. Universidad Estatal Peninsula de Santa Elena, https://repositorio.upse.edu.ec/xmlui/handle/46000/3158

Sani, A., \& Nunes, L. M. (2016). Diagnóstico de seguridad/inseguridad. Un estudio exploratorio en una comunidad urbana. Anuario de Psicología Jurídica, 26(1), 102-106. https://doi.org/10.1016/j.apj.2015.07.001.

Silva, N. M. P. da. (2010). Cidadania e Segurança: Uma Análise Prospectiva. Congresso Nacional de Segurança e Defesa - Centro de Congressos de Lisboa. http://icnsd. afceaportugal.pt/conteudo/congresso/ICNSD_4H_texto_pdf_nuno_parreira_silva. pdf.

Soleto Muñoz, H. (2007). Mediación laboral. Mediación comunitaria. Mediación y Solución de Conflictos: Habilidades Para Una Necesidad Emergente, 331-344. http://dialnet.unirioja.es/servlet/extart?codigo=2504536.

Uprimny, R. (2005). Jueces de Paz y justicia informal: Una aproximación conceptual a sus potencialidades y limitaciones. Dejusticia. Derecho-Justicia - Sociedad. https:// www.dejusticia.org/wpcontent/uploads/2017/04/fi_name_recurso_51.pdf.

Villeda, B. J. S., \& Gómez, G. de J. G. (2019). Genealogía de la mediación comunitaria en México. JUSTICIA, 35, 1-20. https://doi.org/10.17081/just.24.35.3399.

(UCA), U. C. J. S. C., \& (CPDA), E. de C. de paz D. A. (2012). Construcción de paz y prevención de la violencia: perspectivas y aprendizajes desde abajo. En L. Sablich (Ed.), SSRN Electronic Journal Vinculos "“Espacios seguros para mujeres y jovenes en America Latina y el Caribe”» (pp. 97-126). http://bibliotecadigital.udea.edu.co/ handle/10495/13443 